\title{
Survival at one year in patients with lung cancer in a tertiary care center
}

\author{
Sreekala $C^{1}$, K. Anitha Kumari ${ }^{2}$, Jayaprakash B ${ }^{3}$, C Sudheendra Ghosh ${ }^{4}$ \\ ${ }^{1}$ Dr. Sreekala C, ${ }^{2}$ Dr. K. Anitha Kumari, ${ }^{3}$ Dr. Jayaprakash B, ${ }^{4}$ Dr C Sudheendra Ghosh all authors are affiliated with \\ Department of Pulmonary Medicine, Medical College, Thiruvananthapuram, Kerala, India.
}

Address for Correspondence: Dr. Sreekala C, Navaneetham, APRA 307, Ajantha Pulli Lane, Pettah. PO, Chackai, Thiruvananthapuram. Email:drkalamurali@yahoo.co.in

\begin{abstract}
Introduction: Lung cancer is a leading cause of mortality worldwide and despite advances in treatment, prognosis of advanced lung cancer is extremely poor, with a median survival time of approximately 1year. Factors like age, sex, performance status at the time of diagnosis, histological type, extent of disease, smoking status were found to predict survival in lung cancer. Aim of the study: To determine one year survival of lung cancer patients from the date of diagnosis and to evaluate factors that are associated with survival. Methodology: Prospective cohort study, conducted at Medical College, Thiruvananthapuram, Kerala, in 160 consecutive patients with histopathological diagnosis of lung cancer. Data on demography, symptoms, smoking status, performance status according to WHO performance scale, histological diagnosis, TNM stage and death were recorded using a structured questionnaire. Proportion of patients who survived at one year from the date of diagnosis was determined. For inferential statistics between groups, comparison of qualitative variables were analysed by chi-square test and quantitative variables were compared by student $\mathrm{t}$ test. $\mathrm{P}$ value of less than 0.05 was considered as level of significance Cox proportional hazard model were used to evaluate the factors affecting survival of lung cancer patients. Results: 160 consecutive lung cancer patients with histopathological diagnosis were included in the study. $86.9 \%$ of patients were males. Male to Female ratio is $6.6: 1.84 .5 \%$ of patients were above the age of 50 years. $11.3 \%$ were nonsmokers. COPD was the commonest comorbidity $(58 \%)$ in the study. Adenocarcinoma (41.9\%) was the commonest histological type in our study and this was the commonest histological type seen in females and nonsmokers. In smokers, squamous cell carcinoma $(91.3 \%)$ was more common. $66.9 \%$ of patients were at TNM stage 3 or 4 at the time of diagnosis. $17.5 \%$ patients survived at one year after diagnosis. Age more than 70 years, high smoking index, associated COPD, TNM Stage $3 \& 4$, poor performance status at the time of diagnosis were associated with poor survival. ( $\mathrm{p}$ value $<0.001$ ). Squamous cell carcinoma had better survival compared to other histological types $(\mathrm{p}<0.001)$. No significant association between gender and survival pattern was seen in the study. Conclusion: We found that $17.5 \%$ of lung cancer patients survived at one year after diagnosis. There was significant association of factors like age, smoking status, comorbidities, histological type, TNM stage and performance status at diagnosis with survival pattern. But no significant association between gender and survival was found in our study.
\end{abstract}

Keywords: Lung Cancer, Survival, Performance status (PS), Small cell cancer (SCC), Nonsmall lung cancer (NSCLC)

\section{Introduction}

Lung cancer is one of the commonest cause of cancer related deaths all over the world. It accounts for $13 \%$ of the total number of new cases of all cancers and 19 per cent of cancer related deaths worldwide [1]. There were 1.8 million new lung cancer cases estimated to occur in

Manuscript received: $18^{\text {th }}$ March 2017

Reviewed: $26^{\text {th }}$ March 2017

Author Corrected: $3^{\text {rd }}$ April 2017

Accepted for Publication: 10 $0^{\text {th }}$ April 2017
2012. In India, lung cancer constitutes 6.9 per cent of all new cancer cases and 9.3 per cent of all cancer related deaths in both sexes, with the highest reported incidences from Mizoram [2]. The time trends of lung cancer show a significant rise in Delhi, Chennai and Bengaluru in both sexes [2]. The incidence and pattern of lung cancer differ as per geographic region and ethnicity and largely reflect the prevalence and pattern 
of smoking. The overall 5-year survival rate of lung cancer is dismal with approximately 15 per cent in developed countries and 5 per cent in developing countries [3]. In Kerala scenario, $20.1 \%$ of all male cancers are due to Lung cancer [4].

In the Western countries and most of the Asian countries adenocarcinoma has surpassed squamous cell carcinoma [5,6]. This shift might be attributable partly to the smoking habits, particularly filtered cigarettes; moreover, there is also increasing incidence of lung cancer in females and non smokers [5,7,8] Studies showed that men who had never smoked, had higher age-standardized lung cancer death rates than women [7]. Lung cancer in never smokers is an important public health issue, and further exploration of its incidence patterns, etiology, and biology is needed [8]. Most of the previous Indian studies have described squamous cell carcinoma as the commonest histology $[9,10]$ however, some recent studies from two major centers are showing a changing pattern in India [11,12].

No weight loss at the time of diagnosis was a significant predictor for long survival in addition to younger age, limited stage, good functional performance and surgical treatment [13]. The majority of mortalities occurred in elderly patients. The median survival time of elderly patients was significantly lower compared with that of younger patients [14]. The 1-year survival rates in younger and elderly patients were 67.3 and $42.5 \%$, respectively [14]. In multivariate analysis, elderly patients also had significantly poorer survival. In the group of elderly patients, analyses revealed that significant prognostic factors, including stage of disease and serum lactate dehydrogenase (LDH) levels, were associated with survival [14] .The stage at diagnosis was a critical factor that affected the survival of lung cancer patients. So it is essential to develop early diagnosis of lung cancer [15]. The most common comorbid conditions reported are chronic pulmonary disease $(52.5 \%)$, diabetes $(15.7 \%)$, and congestive heart failure $(12.9 \%)$. The adjusted overall survival of lung cancer patients was negatively associated with the existence of different comorbid conditions such as congestive heart failure, diabetes with complications, moderate or severe liver disease, dementia, renal disease, and COPD, depending on the stage [16]. The presence of comorbid conditions were associated with worse survival and different comorbid conditions were associated with worse outcomes at different stages [16]. There is poor prognosis across histologic subtypes in stage IV NSCLC patients. More research using other sources of population-based data could help to clarify the role of histology in the presentation, management, and prognosis of late-stage NSCLC [17]. Current smoking at diagnosis is an important independent predictor of shortened lung cancer survival. This effect is not explained by sociodemographic/exposure factors, adverse symptoms, histology, stage, comorbidity, and treatment suggests that it may be mediated through direct biological effects [18]. Nonsmokers have a 20 to 30 percent greater chance of developing lung cancer if they are exposed to secondhand smoke at home or work. Men who smoke are 23 times more likely to develop lung cancer. Nonsmokers have a 20 to 30 percent greater chance of developing lung cancer if they are exposed to secondhand smoke at home or work [19]. Aim of this study was to determine one year survival of lung cancer patients, from the date of diagnosis and to evaluate the factors affecting survival in patients attending a tertiary care center. These factors associated with survival may be used to develop prediction models in newly detected lung cancer.

\section{Methodology}

Aim of study. To determine one year survival of lung cancer patients from the date of diagnosis and to evaluate factors that are associated with survival. Study Design. A prospective cohort study over a period of two years.

Study Setting: Department of Pulmonary Medicine and Department of Oncology, Medical College, Thiruvananthapuram. Study population: 160 consecutive patients with histopathological diagnosis as lung cancer, diagnosed at Pulmonary Medicine department or cases of lung cancers referred from elsewhere to Department Oncology, Medical College, Thiruvananthapuram, Kerala for a period of two years. Inclusion criteria: All cases of lung cancer with histological proof, willing to participate in the study were included. Exclusion criteria: Patients with malignancies other than lung cancer were excluded. Data collection: Information on demography, symptomatology, histopathological type of lung cancer, extent of disease according TNM classification, performance status of patients at the time of diagnosis by WHO performance scale, smoking status, comorbidities, treatment details, address and phone numbers were collected by patient interview and medical records using structured questionnaire, after getting written consent from patients. Further follow up was done in every 3 months overphone or from 
oncology department records. Data about health status of patients or date of death were recorded in every 3 months. Institutional ethical committee clearance was obtained before collecting data.

Statistical analysis: Data were entered in Microsoft Excel and analyzed using SPSS 10 version.
For inferential statistics between groups, comparison of qualitative variables were analysed by chi-square test and quantitative variables were compared by student $t$ test.

$\mathrm{P}$ value of less than 0.05 was considered as level of significance

\section{Results}

160 consecutive lung cancer patients with histopathological diagnosis were included in the study. 139 (86.9\%) were males and $29(13.1 \%)$ were females.Male to Female ratio is $6.6: 1.84 .5 \%$ of patients were above the age of 50 years and $2.5 \%$ were below 40 years $.11 .3 \%$ were nonsmokers. $80.6 \%$ of smokers were having smoking index $>200$. Hemoptysis was present in $38 \%$ of patients.COPD was the commonest comorbidity (58\%), followed by anemia (50\%). Commonest histological type was Adenocarcinoma (41.9\%). Adenocarcinoma was the commonest histological type seen in females and nonsmokers. In smokers, squamous cell carcinoma was the commonest histological type (91.3\%) found, in the study. Small cell cancer (SCC) occurred in $16.3 \%$ of patients.66.9\% NSCLC of patients were at TNM stage 3 or 4 at the time of diagnosis whereas an $80.3 \%$ of SCC were at extensive stage. Only 5\% of patients underwent surgery. $17.5 \%$ patients survived at one year after diagnosis.

Table-1: Survival function of age

\begin{tabular}{|c|c|c|c|c|c|}
\hline \multirow{2}{*}{$\begin{array}{c}\text { Age } \\
\text { (in years) }\end{array}$} & \multicolumn{4}{|c|}{ Survival } & \multirow{2}{*}{ Total } \\
\hline & $<3$ months & 3 - 6 months & 6 - 12 months & $>1$ year & \\
\hline \multirow{2}{*}{$30-39$} & 4 & - & - & - & 4 \\
\hline & $6.60 \%$ & & & & $2.50 \%$ \\
\hline \multirow[t]{2}{*}{$40-49$} & - & 4 & 7 & 10 & 21 \\
\hline & & $11.80 \%$ & $18.90 \%$ & $35.70 \%$ & $13.10 \%$ \\
\hline \multirow{2}{*}{$50-59$} & 18 & 15 & 13 & 16 & 62 \\
\hline & $29.50 \%$ & $44.10 \%$ & $35.10 \%$ & $57.10 \%$ & $38.80 \%$ \\
\hline \multirow[t]{2}{*}{$60-69$} & 17 & 5 & 6 & 2 & 30 \\
\hline & $27.90 \%$ & $14.70 \%$ & $16.20 \%$ & $7.10 \%$ & $18.80 \%$ \\
\hline \multirow[t]{2}{*}{$>=70$} & 22 & 10 & 11 & - & 43 \\
\hline & $36.10 \%$ & $29.40 \%$ & $29.70 \%$ & & $26.90 \%$ \\
\hline
\end{tabular}

Chi square: $45.321 ; \mathrm{p}<0.001$

Age more than 70 years was found to be associated with poor survival. $(\mathrm{p}<0.001)$.

Table-2: Survival function of smoking.

\begin{tabular}{|c|c|c|c|c|c|}
\hline \multirow{2}{*}{ History of smoking } & \multicolumn{4}{|c|}{ Survival } & \multirow{2}{*}{ Total } \\
\cline { 2 - 6 } & $\mathbf{< 3 ~ m o n t h s}$ & $\mathbf{3 - 6}$ months & $\mathbf{6}$ - 12 months & > 1 year & 18 \\
\hline \multirow{2}{*}{ Non smoker } & 3 & 3 & 6 & 6 & $11.30 \%$ \\
\cline { 2 - 6 } & $4.90 \%$ & $8.80 \%$ & $16.20 \%$ & $21.40 \%$ & 13 \\
\hline \multirow{2}{*}{$50-200$} & 7 & - & 2 & 4 & $8.10 \%$ \\
\cline { 2 - 6 } & $11.50 \%$ & & $5.40 \%$ & $14.30 \%$ & 21 \\
\hline \multirow{2}{*}{$200-500$} & 6 & 4 & 6 & $17.90 \%$ & $13.10 \%$ \\
\cline { 2 - 6 } & $9.80 \%$ & $11.80 \%$ & $16.20 \%$ & 7 & 65 \\
\hline \multirow{2}{*}{$500-1000$} & 29 & 19 & $18.90 \%$ & $35.70 \%$ & $40.60 \%$ \\
\cline { 2 - 6 } & $47.50 \%$ & $55.90 \%$ & 16 & 3 & 43 \\
\hline \multirow{2}{*}{$>1000$} & 16 & 8 & $43.20 \%$ & $10.70 \%$ & $26.90 \%$ \\
\hline
\end{tabular}

Chi square: $25.974 ; \mathrm{p}<0.05$

High smoking index was an independent predictor of survival in the study. $(\mathrm{p}<0.001)$. 
Table-3: survival function of histology.

\begin{tabular}{|c|c|c|c|c|c|}
\hline \multirow{2}{*}{ Histology } & \multicolumn{4}{|c|}{ Survival } & \multirow{2}{*}{ Total } \\
\hline & $<3$ months & 3 - 6 months & 6 - 12 months & $>1$ year & \\
\hline \multirow{2}{*}{ Squamous cell carcinoma } & 8 & 6 & 12 & 20 & 46 \\
\hline & $13.10 \%$ & $17.60 \%$ & $32.40 \%$ & $71.40 \%$ & $28.80 \%$ \\
\hline \multirow[t]{2}{*}{ Adino carcinoma } & 26 & 15 & 20 & 6 & 67 \\
\hline & $42.60 \%$ & $44.10 \%$ & $54.10 \%$ & $21.40 \%$ & $41.90 \%$ \\
\hline \multirow[t]{2}{*}{ Small cell carcinoma } & 16 & 6 & 2 & 2 & 26 \\
\hline & $26.20 \%$ & $17.60 \%$ & $5.40 \%$ & $7.10 \%$ & $16.30 \%$ \\
\hline \multirow[t]{2}{*}{ Large cell carcinoma } & 4 & - & - & - & 4 \\
\hline & $6.60 \%$ & & & & $2.50 \%$ \\
\hline \multirow[t]{2}{*}{ Non-specific } & 7 & 7 & 3 & - & 17 \\
\hline & $11.50 \%$ & $20.60 \%$ & $8.10 \%$ & & $10.60 \%$ \\
\hline
\end{tabular}

Chi square: $49.505 ; \mathrm{p}<0.001$

Squamous cell carcinoma had a better survival compared to other histological type. $(\mathrm{p}<0.001)$.

Table-4 Survival pattern in relation to TNM staging.

\begin{tabular}{|c|c|c|c|c|c|}
\hline \multirow{2}{*}{ TNM(NSCLC) } & \multicolumn{4}{|c|}{ Survival } & \multirow{2}{*}{ Total } \\
\hline & $<3$ months & 3 - 6 months & 6 - 12 months & $>1$ year & \\
\hline \multirow[t]{2}{*}{ Stage I } & - & - & - & 3 & 3 \\
\hline & & & & $10.70 \%$ & $1.90 \%$ \\
\hline \multirow[t]{2}{*}{ Stage II } & - & - & - & 22 & 22 \\
\hline & & & & $78.60 \%$ & $13.80 \%$ \\
\hline \multirow[t]{2}{*}{ Stage IIIa } & - & 4 & 11 & - & 15 \\
\hline & & $11.80 \%$ & $29.70 \%$ & & $9.40 \%$ \\
\hline \multirow[t]{2}{*}{ Stage IIIb } & 5 & 5 & 11 & - & 21 \\
\hline & $8.20 \%$ & $14.70 \%$ & $29.70 \%$ & & $13.10 \%$ \\
\hline \multirow[t]{2}{*}{ Stage IV } & 31 & 16 & 2 & - & 49 \\
\hline & $50.80 \%$ & $47.10 \%$ & $5.40 \%$ & & $30.60 \%$ \\
\hline \multirow[t]{2}{*}{ Limited stage (SCC) } & - & - & 3 & 2 & 5 \\
\hline & & & $8.10 \%$ & $7.10 \%$ & $3.10 \%$ \\
\hline \multirow[t]{2}{*}{ Extensive stage(SCC) } & 16 & 6 & - & - & 22 \\
\hline & $26.20 \%$ & $17.60 \%$ & & & $13.80 \%$ \\
\hline \multirow[t]{2}{*}{ Stage unkonwn } & 9 & 3 & 10 & 1 & 23 \\
\hline & $14.80 \%$ & $8.80 \%$ & $27.00 \%$ & $3.60 \%$ & $14.40 \%$ \\
\hline
\end{tabular}

Chi square: $213.488 ; \mathrm{p}<0.001$

TNM Stage $3 \& 4$, at presentation was an independent factor that predict poor survival in lung cancer in our study ( $<<$ 0.002). Extensive stage of SCC predict poor prognosis.

WHO Performance score $2,3 \& 4$ at the time of diagnosis were associated with poor survival. $(\mathrm{p}<0.001)$ Associated comorbidities like COPD, was predictor of poor survival in our study. $(\mathrm{p}<0.001)$

No significant association between gender and survival pattern was seen in the study. 


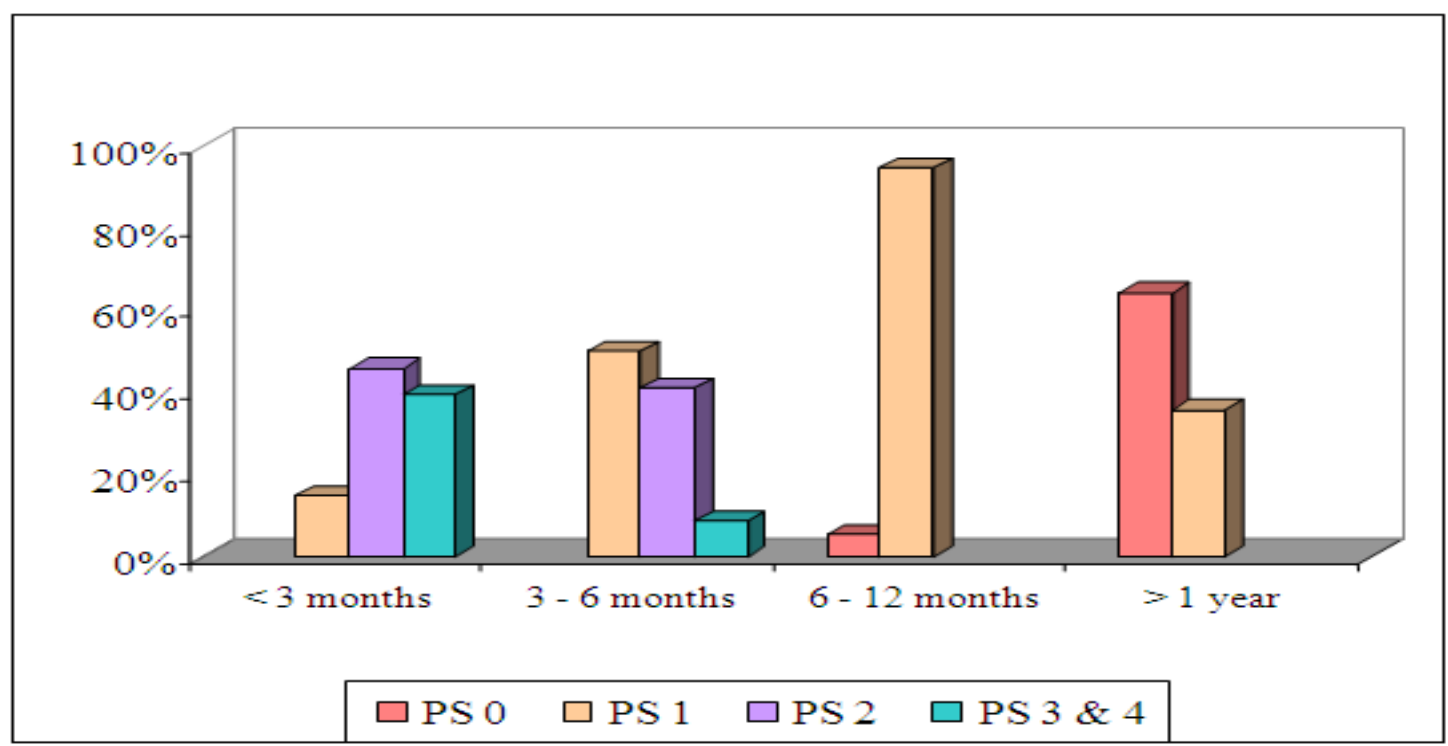

Fig-1: survival pattern in relation to performance status (WHO performance score)

\section{Discussion}

The five-year survival rate for lung cancer is 55 percent for cases detected when the disease is still localized (within the lungs). However, only 16 percent of lung cancer cases are diagnosed at an early stage. For extensive stage disease the five-year survival rate is only 4 percent. The lung cancer five-year survival rate (17.7 percent) is lower than many other leading cancer sites [19]. More than half of people with lung cancer die within one year of being diagnosed [19]. Exposure to second hand smoke causes approximately 7,330 lung cancer deaths among nonsmokers every year [19]. Previous studies carried out to find out survival pattern and factors predicting survival showed conflicting results $[14,20]$.

Our study showed a male to female ratio of $6.6: 1$ and age group commonly affected was 50 - 59 years, findings correlating with results of other Indian study [4]. According to study by Malik PS et al median age of lung cancer patients was 55 years with a male:female ratio of $4.6: 1 .[12]$.

$11.3 \%$ were nonsmokers in our study. Previous studies also reported the increasing incidence of lung cancer in females and non smokers $[7,8]$.

Adenocarcinoma was the most common histological type encountered in our study $(41.9 \%)$, a result similar to Indian study [4], but KilHoi Lee et al reported squamous cell carcinoma (39.7\%) as the most frequent histological type, followed by adenocarcinoma $25.5 \%$
[15]. In the Western countries and most of the Asian countries adenocarcinoma has surpassed squamous cell carcinoma [5,6]. This shift might be attributable partly to the smoking habits, particularly filtered cigarettes. Recent studies from two major centres are showing a changing pattern in India also.[11,12].

COPD (58\%) was the commonest comorbidity in our study. Similar finding was reported by Islam K M et al, where prevalence of COPD in lung cancer was $52.5 \%$ [16].

$66.9 \%$ of patients with NSCLC were at TNM stage 3 or 4 at the time of diagnosis and among SCC $80.3 \%$ had extensive disease in this study as reported earlier [4].

Malik PS et al reported that $56.8 \%$ cases were of stage IV while among SCLC $71.8 \%$ cases had extensive stage disease [12].

$17.5 \%$ patients survived at one year after diagnosis in our study, similar to the result in earlier study by P.A. Mahesh et al [6]. Malik PS et al reported that the median overall and progression free survivals of the patients who received treatment were 12.8 months [12].

Age more than 70 years at diagnosis was associated with poor survival in our study similar to the result of study by FarukTas et al.where median survival time of elderly patients was significantly lower compared with that of younger patient [14]. 
Lung cancer patients with COPD had higher mortality in the study.Studies by Islam KM et al and C.Martin et al also showed similar results $[16,18,20]$. Performance status 2,3 \& 4 (according to WHO Performance scale) at the time of diagnosis were found to be associated with poor survival in our study. Earlier studies also demonstrated that poor performance status at diagnosis was associated with decreased survival time [13]. High smoking index was found to be an independent predictor of survival in the study. Study by Seung Jun Lee, et al reported an overall mortality of ever-smokers was higher than that of never-smokers in patients with newly diagnosed NSCLC, and current smoking was an independent risk factor for a poorer prognosis [18,21].

Squamous cell carcinoma was found to have better prognosis compared to other histological types in our study as reported earlier by Karynsa Cetin et al [17]. TNM stage was independent prognostic factor that predicted survival in this study. Kil Hoi Lee,et al also reported that stage of lung cancer was an independent factor associated with survival [15]. Our results showed no significant association between survival pattern and gender,butKil Hoi Lee et alreported that survival rate in females was higher than that of males [15].

\section{Conclusion.}

$17.5 \%$ of lung cancer patients survived at one year after diagnosis. There was significant association of factors like age, smoking status, comorbidities, histological type, TNM stage and performance status at diagnosis with survival pattern, a finding that may help in developing prediction model for prognostication of lung cancer at the time of diagnosis.

Conflict of interest: None. Funding: Nil

Permission of IRB: Yes

\section{References}

1. Ferlay J, Soerjomataram I, Ervik M, Dikshit R, Eser S, Mathers C, Rebelo M, Parkin DM, Forman D, Bray, F.GLOBOCAN 2012 v1.1, Cancer Incidence and Mortality Worldwide: IARC CancerBase No. 11 [Internet]. Lyon, France: International Agency for Research on Cancer; 2014. Available from: http: // globocan. iarc.fr, accessed on 16/01/2015.

2. Indian Council of Medical Research; 2013. [accessed on January 21, 2014]. National Cancer Registry Programme. Three Year Report of Population Based
Cancer Registries: 2009-2011. Available from: http:// www. ncrpindia.

3. Parkin DM, Bray F, Ferlay J, Pisani P. Global cancer statistics, 2002. CA Cancer J Clin. 2005 Mar-Apr; 55 (2): 74-108.

4. Bhaskarapillai B, Kumar SS, Balasubramanian S. Lung cancer in Malabar Cancer Center in Kerala--a descriptive analysis. Asian Pac J Cancer Prev. 2012; 13 (9): 4639-43.

5. Valaitis J, Warren S, Gamble D. Increasing incidence of adenocarcinoma of the lung. Cancer. 1981 Mar 1;47 (5):1042-6.

6. Janssen-Heijnen ML, Coebergh JW. The changing epidemiology of lung cancer in Europe. Lung Cancer. 2003 Sep;41(3):245-58.

7. Thun MJ, Henley SJ, Burns D, Jemal A, Shanks TG, Calle EE. Lung cancer death rates in lifelong nonsmokers. J Natl Cancer Inst. 2006 May 17; 98 (10):691-9.

8. Wakelee HA, Chang ET, Gomez SL, Keegan TH, Feskanich D, Clarke CA, Holmberg L, Yong LC, Kolonel LN, Gould MK, West DW. Lung cancer incidence in never smokers. J Clin Oncol. 2007 Feb 10; 25 (5):472-8.

9. Behera D, Balamugesh T. Lung cancer in India. Indian J Chest Dis Allied Sci. 2004 Oct-Dec; 46(4): 269-81.

10. Singh N, Aggarwal AN, Gupta D, Behera D, Jindal SK. Unchanging clinico-epidemiological profile of lung cancer in north India over three decades. Cancer Epidemiol. 2010;34:101-4. [PubMed]

11. Noronha V, Dikshit R, Raut N, Joshi A, Pramesh CS, George K, Agarwal JP, Munshi A, Prabhash K. Epidemiology of lung cancer in India: focus on the differences between non-smokers and smokers: a single-centre experience. Indian J Cancer. 2012 JanMar; 49(1):74-81. doi: 10.4103/0019-509X.98925.

12. Malik PS, Sharma MC, Mohanti BK, Shukla NK, Deo S, Mohan A, et al. Clinico-pathological profile of lung cancer at AIIMS: a changing paradigm in India. Asian Pac J Cancer Prev. 2013;14:489-94. [PubMed. 
13. Skaug K, Eide GE, Gulsvik A. Predictors of longterm survival of lung cancer patients in a Norwegian community. Clin Respir J. 2011 Jan; 5 (1):50-8. doi: 10. 1111/j. 1752-699X.2010.00200.x.

14. Tas F, Ciftci R, Kilic L, Karabulut S. Age is a prognostic factor affecting survival in lung cancer patients. Oncol Lett. 2013 Nov; 6(5):1507-1513. Epub 2013 Sep 6.

15. Kil Hoi Lee, Yunhyung Kwon, Tae Yong Lee. Survival Rate and Factors Affecting Survival among Patients of Lung Cancer Lived in Daejeon City. Korean Journal of Epidemiology 2003;25(2): 62-75.

16. Islam KM, Jiang X, Anggondowati T, Lin G, Ganti AK. Comorbidity and Survival in Lung Cancer Patients. Cancer Epidemiol Biomarkers Prev. 2015 Jul; 24(7): 1079-85. doi: 10.1158/1055-9965.EPI-15-0036. Epub 2015 Jun 11.

17. Karynsa Cetin, David S Ettinger, Yong-jiangHei, et al Survival by histologic subtype in stage IV nonsmall cell lung cancer based on data from the Surveillance,
Epidemiology and End Results Program Clin Epidemiol. 2011; 3: 139-148.

18. Tammemagi CM, Neslund-Dudas C, Simoff M, Kvale P. Smoking and lung cancer survival: the role of comorbidity and treatment. Chest. 2004 Jan; 125(1): 27-37.

19. Lung Cancer Fact Sheet | American Lung Association1- 800- LUNGUSA. www. lung.org/ lung health-and.../lung-disease.../lung-cancer/.../lung-cancerfact-sheet.

20. P.A. MaheshS. ArchanaB.S. Jayaraj ,ShekarPatil, S.K. Chaya, H.P. Shashidha, Sunitha:Factors affecting 30 -month survival in lung cancer patients. Indian $\mathbf{J}$ of Med Res136, 2012 pp614 -621

21. Lee SJ, Lee J, Park YS, Lee CH, Lee SM, Yim JJ, Yoo CG, Han SK, Kim YW. Impact of smoking on mortality of patients with non-small cell lung cancer. Thorac Cancer. 2014 Jan;5(1):43-9. doi: 10.1111/17597714.12051. Epub 2014 Jan 2.

\section{How to cite this article?}

Sreekala C, K. Anitha Kumari, Jayaprakash B, C Sudheendra Ghosh. Survival at one year in patients with lung cancer in a tertiary care center. Int J Med Res Rev 2017;5(4):374-380. doi: 10.17511/ijmrr.2017.i04.01. 